\title{
Analysis of Molten Metal Distribution in the Mold of a Horizontal Centrifugal Casting
}

\author{
Miguel A. Barron*, Dulce Y. Medina, Joan Reyes \\ Departamento de Materiales, Universidad Autonoma Metropolitana Azcapotzalco, Mexico City, Mexico \\ Email: `bmma@correo.azc.uam.mx, dyolotzin@azc.uam.mx, joremi@azc.uam.mx
}

How to cite this paper: Barron, M.A., Medina, D.Y. and Reyes, J. (2020) Analysis of Molten Metal Distribution in the Mold of a Horizontal Centrifugal Casting. Open Journal of Applied Sciences, 10, 444-454. https://doi.org/10.4236/ojapps.2020.107031

Received: June 13, 2020

Accepted: July 14, 2020

Published: July 17, 2020

Copyright $\odot 2020$ by author(s) and Scientific Research Publishing Inc. This work is licensed under the Creative Commons Attribution International License (CC BY 4.0).

http://creativecommons.org/licenses/by/4.0/

\begin{abstract}
It is numerically studied the influence of the angular velocity, the molten metal viscosity, and the mold wall roughness on the molten metal distribution in the mold of a horizontal centrifugal casting process. The undesirable raining phenomenon sometimes arises in horizontal centrifugal casting. It occurs when the molten metal rains or falls from the top of the mold to the bottom while the mold is rotating. Using Computational Fluid Dynamics simulations, the conditions for the emergence of the raining phenomenon were explored in this work. For the system considered, angular velocities less than $77 \mathrm{rad} / \mathrm{s}$ cause the emergence of the raining phenomenon and accumulation of the molten metal in the lower part of the mold, whereas angular velocities greater than $77 \mathrm{rad} / \mathrm{s}$ produce a constant thickness of the molten metal and prevent raining.
\end{abstract}

\section{Keywords}

Angular Velocity, Centrifugal Casting, Computational Fluid Dynamics, Molten Metal, Viscosity, Wall Roughness

\section{Introduction}

Centrifugal casting accounts for $15 \%$ of the total casting output of the world in terms of tonnage [1]. The centrifugal casting process consists in pouring molten metal into a rotating mold. The mold is rotated about a horizontal axis, see Figure 1, or a vertical axis and the metal is thrown against the inner mold wall [2]. Rotation is maintained until the complete solidification of the molten metal. A high pressure is developed in the centrifugal casting process during directional solidification. This promotes metal degassing and the separation of non-metallic inclusions, which are collected in the inner wall of the product and are easily removed by machining. The main advantages of centrifugal casting are the sui- 
tability for casting cylindrical forms and the high metallurgical quality of the product [3]. This process is usually used for manufacturing hollow castings with axis-symmetric shapes, e.g. pipes for water and oil industries, without the use of cores [2] [4]. The centrifugal effect produces an increase in rupture strength around $50 \%$, in rupture strain in about $300 \%$, and the Young modulus increases about $20 \%$ as compared to the gravity casting [5].

Equiaxed grains are formed during solidification. These grains oscillate with a frequency and amplitude which depend on the rotation rate. The amplitude of oscillation of equiaxed grains decreases with increasing rotation rate and these grains travel backwards with respect to the rotation direction [6]. Researchers from academy and industry have tackled the study of centrifugal casting using cold physical models and mathematical models. In [7] an experiment using a laboratory plexi-glass mold with water as a working fluid is reported. The mold rotations were gradually increased in order to determine the rotation speed at which the transition from the liquid pool to a uniform liquid layer occurs. In [8] [9] visualization experiments on cold models and numerical simulations of the flow field have been carried out for a centrifugal casting system with horizontal molds and fluids of different viscosities to analyze the effect of different process variables on the flow pattern. The effect of the thickness of the fluid layer, viscosity of the fluid, diameter of the mould, and rotational speed of the mould on the formation of a hollow fluid cylinder were studied.

Related to numerical modeling, in [10] a three-dimensional mathematical model and a physical model coupled with heat transfer and electromagnetic forces in the centrifugal casting process were proposed. The distribution of the temperature and flow fields in the centrifugal casting under the gravity, the electromagnetic stirring force and the centrifugal force were analyzed. A numerical model based on the shallow water equations was proposed to simulate the two-dimensional average flow dynamics of the liquid metal spreading inside a horizontally rotating mold [11]. In [12] a mathematical model for a horizontal centrifugal pipe casting process was developed. The authors consider the friction between the liquid and the mold in connection with the viscosity and turbulence of the molten metal. Friction coefficients for the description of the interaction between mold and melt were reported. The most important effect of roughness is the change of the mean velocity profile near the wall, with the consequent modification of the friction coefficient [13] [14].

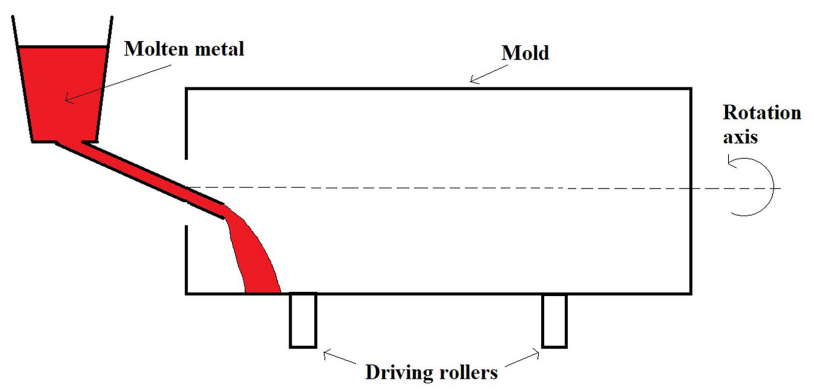

Figure 1. The horizontal centrifugal casting process. 
The raining phenomenon sometimes arises in horizontal centrifugal casting. It occurs when the molten metal rains or falls from the top of the mold to the bottom while the mold is rotating [15]. Raining is undesirable given that it causes oxidization of the falling metal, turbulence of the metal in the mold, and significant temperature gradients of the molten metal which decreases directional solidification. Reducing the pouring rate and increasing the rotation speed prevent raining [15]. Unfortunately, the above phenomenon is not enough studied in the literature. In this work the conditions for the emergence of the raining phenomenon were numerically explored using Computational Fluid Dynamics simulations.

The influence of the angular velocity, the molten metal viscosity, and the mold wall roughness on the molten metal distribution inside the mold of a horizontal centrifugal casting process is analyzed here. Using the Computational Fluid Dynamics technique, momentum, mass, turbulence, and multiphase model equations were numerically solved. Numerical transient two-phase isothermal simulations were carried out considering axial symmetry in the system. Besides the molten metal and velocity distributions, it were explored the conditions for the emergence of the raining phenomenon.

\section{Mathematical Model}

The Computational Fluid Dynamics (CFD) technique [16] was employed to study the fluid flow in the horizontal centrifugal casting. A two-phase axisymmetric system formed by molten steel and air was assumed. The process is considered isothermal and no solidification is considered. The equations of continuity and momentum [17], the Volume of Fluid model for multiphase flow [18] and the classical K- $\varepsilon$ model for turbulence [19] were employed in the CFD simulations.

In the horizontal centrifugal casting two main forces are involved in the molten metal flow: the centrifugal forces, and the gravity forces [20]. The first ones are due to the mold rotation, and the second ones are due to the mass of the molten metal. The quotient between the centrifugal forces $\left(F_{c}\right)$ and the gravity forces $\left(F_{g}\right)$ is a dimensionless parameter commonly known as $G$-factor $\left(G_{F}\right)$ [3]:

$$
G_{F}=\frac{F_{c}}{F_{g}}=\frac{v^{2}}{R g}=\frac{R \omega^{2}}{g}
$$

where $v$ is the peripheral speed $(\mathrm{m} / \mathrm{s}), R$ is the mold internal radius $(\mathrm{m}), \omega$ is the angular velocity $(\mathrm{rad} / \mathrm{s})$, and $g$ is the gravity acceleration $\left(\mathrm{m} / \mathrm{s}^{2}\right)$. Manipulation of Equation (1) yields an expression to determine the rotational speed:

$$
N=29.91 \sqrt{\frac{G_{F}}{R}}
$$

where $N$ is the rotational speed (rev/min). For horizontal centrifugal casting, it has been empirically determined that $G_{F}$ must have a value between 60 and 80 in order to obtain the same thickness of the molten and solidified layers around the mold circumference [20]. 


\section{Numerical Simulations}

Numerical transient two-phase isothermal simulations were carried out considering axial symmetry in the system. As the work is mainly focused in the molten metal distribution in the mold, to reduce the computer time no heat transfer and no solidification were considered. Time step of $0.001 \mathrm{~s}$ was employed in the geometrical system with a mesh consisting of 7300 trilateral elements. Run time of the computer simulations was $10 \mathrm{~s}$. Non-slip condition and rotational motion were assumed as boundary conditions at the mold wall.

Given that axial symmetry is assumed, a two-dimensional slice was considered, as is shown in Figure 2. In this figure is depicted is a transverse slice of the centrifugal casting mold before and after rotation, considering that the whole molten metal charge was previously poured. In this figure and in the numerical simulations axial symmetry is assumed. The mold rotates counterclockwise, from right to left, and the mold wall is not shown. The molten metal has an initial depth $h$, and the molten metal layer has a thickness $\delta$ once the steady state has been reached, assuming a proper value of $G_{F}$. Then,

$$
\delta=R-R_{i}
$$

where $R_{i}$ is the internal radius of the molten layer. A mass balance of molten metal inside the mold slice of Figure 2 yields the next expression to determine $R_{i}$ :

$$
R_{i}=\sqrt{R^{2}-\left(\frac{\alpha R^{2}}{180}-\frac{2 a(R-h)}{\pi}\right)}
$$

where the meaning of the angle $\alpha$ (in degrees), the length $a$, and the molten depth $h$ are clearly indicated in Figure 2. The values of $\alpha$ and $a$ are determined using basic principles of trigonometry:

$$
\begin{aligned}
& \alpha=\cos ^{-1}\left(\frac{R-h}{R}\right) \\
& a=\sqrt{R^{2}-(R-h)^{2}}
\end{aligned}
$$

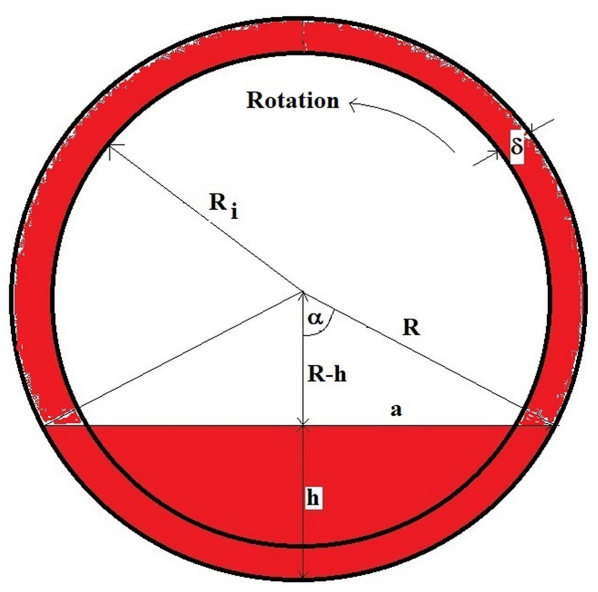

Figure 2. Transverse slice of the centrifugal casting mold before and after rotation. Red phase is the molten metal. 
In the numerical simulations it was assumed that value of the mold radius was $R=0.1 \mathrm{~m}$. and the mold rotates counterclockwise. Besides, three values of the angular velocity, the molten metal viscosity, and the mold wall roughness $(R a)$ were considered, as follows: $\omega=50,60$, and $77 \mathrm{rad} / \mathrm{s} ; \mu=0.002,0.0067$, and 0.01 $\mathrm{kg} /(\mathrm{m} . \mathrm{s}) ; R a=0,0.001$, and $0.005 \mathrm{~m}$, respectively. The cases considered are shown in Table 1 . For $R=0.1 \mathrm{~m}$, Table 1 shows that the first two values of the angular velocity (Cases 5 and 4), namely 50 and $60 \mathrm{rad} / \mathrm{s}$, yield values of the G-factor which are far below the minimum recommended value, i.e. 60 , in order to obtain a uniform thickness of the molten and solidified layers around the mold circumference [20]. This will be corroborated through the results of the numerical simulations.

On the other hand, viscosity measures the internal friction forces in a fluid, and in this way represents the opposition of a fluid to flow. Besides, it is well known that the viscosity of a liquid depends inversely, in a non-linear fashion, on the liquid temperature through an Arrhenius-like behavior [21]. Then, changes in the molten metal viscosity represent, in an inverted way, changes in the molten metal temperature. When the molten metal is close to its solidus temperature, its viscosity suffers and exponential increment. The values of the physical properties of molten metal and air considered in numerical simulations are shown in Table 2. In order to study the influence of the molten metal viscosity on the phase distribution in the mold, three values of this property were considered, as is depicted in Table 2.

Table 1. Cases considered in the numerical simulations.

\begin{tabular}{ccccccc}
\hline Case & $\omega, \mathrm{rad} / \mathrm{s}$ & $\mu, \mathrm{kg} /(\mathrm{m} \cdot \mathrm{s})$ & $R a, \mathrm{~m}$ & $V, \mathrm{~m} / \mathrm{s}$ & $N, \mathrm{rpm}$ & $G$ \\
\hline 1 & 77 & 0.0067 & 0 & 7.7 & 735.1 & 60.4 \\
2 & 77 & 0.0067 & 0.001 & 7.7 & 735.1 & 60.4 \\
3 & 77 & 0.0067 & 0.005 & 7.7 & 735.1 & 60.4 \\
4 & 60 & 0.0067 & 0 & 6.0 & 573.0 & 36.7 \\
5 & 50 & 0.0067 & 0 & 5.0 & 477.6 & 25.5 \\
7 & 77 & 0.010 & 0 & 7.7 & 735.1 & 60.4 \\
\hline
\end{tabular}

Table 2. Values of the physical properties of the considered phases.

\begin{tabular}{cc}
\hline Parameter & Value \\
Molten metal density & $7100 \mathrm{~kg} / \mathrm{m}^{3}$ \\
Molten metal viscosity & $0.002,0.0067,0.01 \mathrm{~kg} /(\mathrm{m} \cdot \mathrm{s})$ \\
Molten metal surface tension & $1.69 \mathrm{~N} / \mathrm{m}$ \\
Air density & $1.225 \mathrm{~kg} / \mathrm{m}^{3}$ \\
Air viscosity & $1.7894 \times 10^{-5} \mathrm{~kg} /(\mathrm{m} \cdot \mathrm{s})$
\end{tabular}


Roughness of the mold wall increases the friction between the molten metal and the mold wall. The most important effects of roughness are the change of the mean velocity profile near the wall and the increment of the adherence of the molten metal to the mold wall [13] [14]. Three values of the mold wall roughness were considered in the computer simulations, as is appreciated in Table 1, which go from a fully smooth wall, i.e. $R a=0$, to significant values of roughness (Cases 2 and 3).

\section{Results and Comments}

Phase distribution inside of the centrifugal casting mold was obtained using the cases of Table 1 and the physical properties of molten metal and air of Table 2. Time evolution of molten metal distribution in the mold for different values of the angular velocity is shown in Figure 3 assuming, as was stated above, that the mold rotates counterclockwise. Time proceeds from left to right, and angular velocity increases from top to bottom. In this figure it is appreciated that as time proceeds the molten metal (in red) is dragged up by the rotating wall. For $\omega=50$ $\mathrm{rad} / \mathrm{s}$ and $\omega=60 \mathrm{rad} / \mathrm{s}$ their corresponding values of the $G$-factor are, in accordance to Table 1, 55.5 and 36.7, respectively. These $G_{F}$ values are, in accordance to [20], far below the minimum recommended value of 60 in order to obtain a uniform thickness of the molten layer in the mold wall. Figure 3 corroborates this empirical recommendation given that the above values of $\omega$ cause that most of the molten metal remain in the lower part of the mold. A homogeneous layer of molten metal is formed for $\omega=77 \mathrm{rad} / \mathrm{s}$, whose corresponding value of $G$-factor is 60.4. Besides, in accordance to Figure 3, for times equal or greater than $1 \mathrm{~s}$, the raining phenomenon arises for the first two values of the angular velocity. Increasing the angular velocity to $77 \mathrm{rad} / \mathrm{s}$, as is reported in [15], prevents the raining phenomenon. This is evident observing Figure 3.

The effect of the molten metal viscosity on the melt distribution is shown in Figure 4. Viscosity influence on the process seems to be important just at the beginning of the mold rotation, given that some raining arises for $\mu=0.002 \mathrm{~kg} /(\mathrm{m} \cdot \mathrm{s})$ and $t=1 \mathrm{~s}$. Besides, in Figure 4 is observed that, for $t=1 \mathrm{~s}$, the molten metal that is located in the upper part of the mold tends to increase as the viscosity is increased. However, as time proceeds the influence of the viscosity is less significant, and for $t$ $=10 \mathrm{~s}$ a uniform layer of molten metal around the mold wall is obtained.

In Figure 5, the evolution of the phase distribution in the centrifugal casting mold for different values of the mold wall roughness is depicted. Roughness enhances the adherence of the molten metal to the mold wall, at least during the beginning of the process, and in Figure 5, it is appreciated that as the roughness is increased the uniformity of the molten layer is enhanced. However, for times greater than $10 \mathrm{~s}$ the effect of the mold wall roughness on the layer uniformity can be neglected. Velocity vectors for the considered values of the angular velocities (Cases 1, 4 and 5) are shown in Figure 6 for time $=10 \mathrm{~s}$. Disorder of the flow decreases as the angular velocity is increased. Figure 6(c) shows that a fully concentric flow pattern is obtained for $\omega=77 \mathrm{rad} / \mathrm{s}$. 

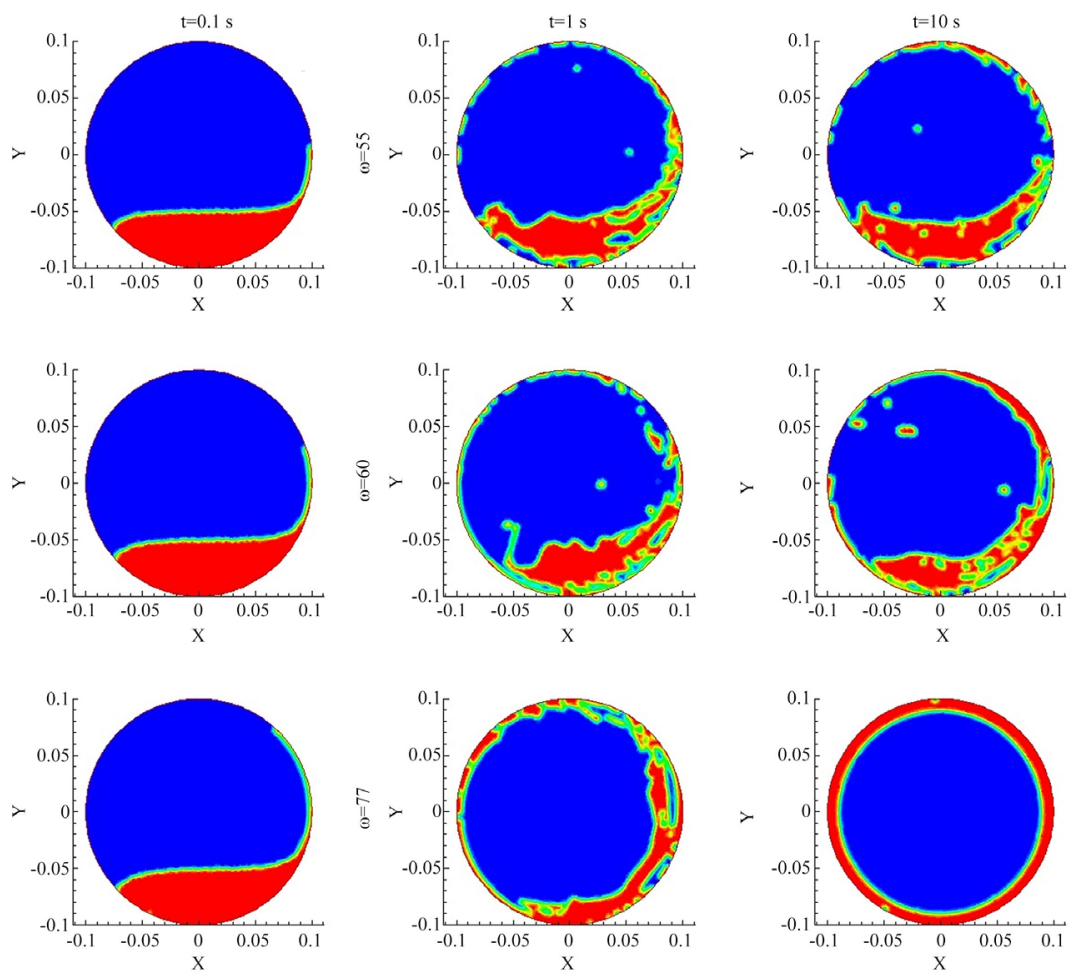

Figure 3. Evolution of the molten metal distribution in the centrifugal casting mold for different values of the mold angular velocity and time. Red phase is molten steel, blue phase is air.
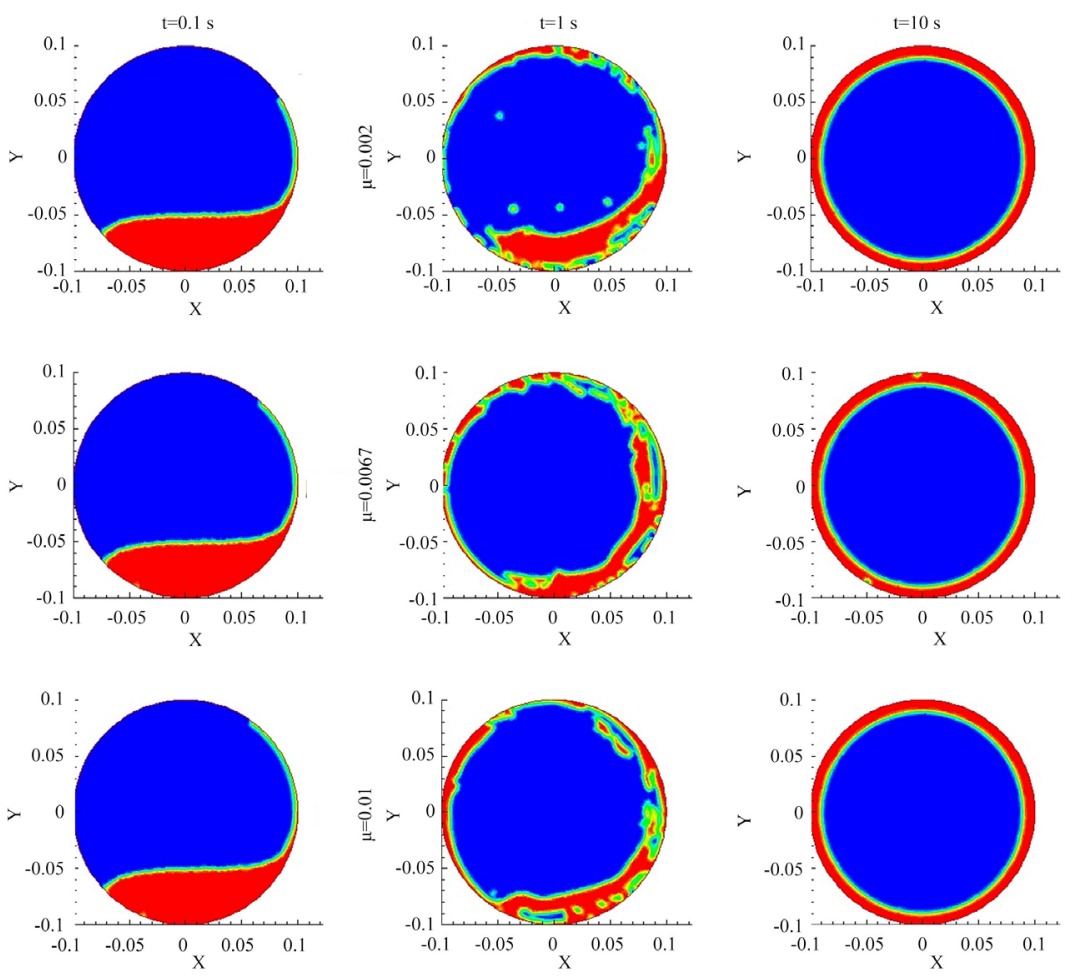

Figure 4. Evolution of the molten metal distribution in the centrifugal casting mold for different values of the molten metal viscosity and time. Red phase is molten steel, blue phase is air. 

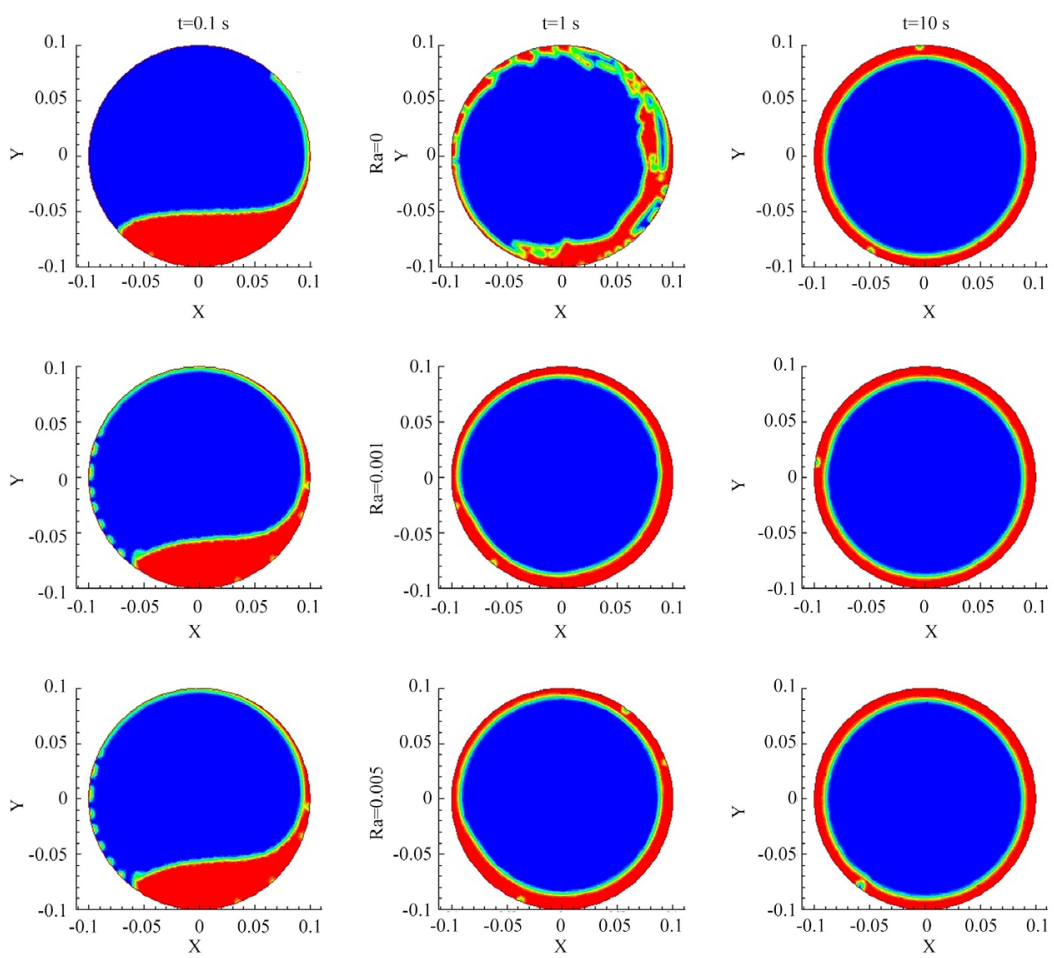

Figure 5. Evolution of the molten metal distribution in the centrifugal casting mold for different values of the mold wall roughness and time. Red phase is molten steel, blue phase is air.

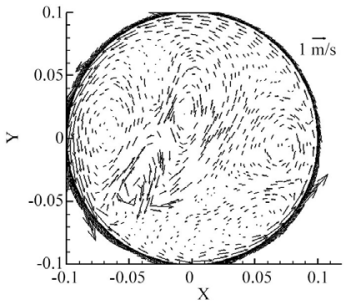

(a)

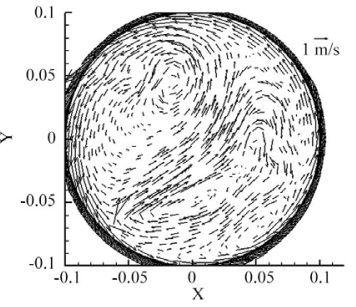

(b)

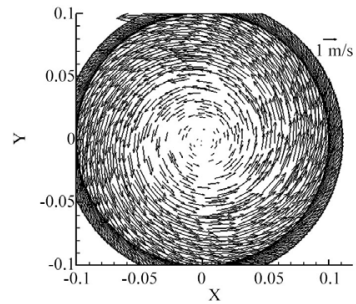

(c)

Figure 6. Velocity vectors for $t=10 \mathrm{~s}$ as function of the angular velocity. (a) $\omega=50 \mathrm{rad} / \mathrm{s}$, (b) $\omega=60 \mathrm{rad} / \mathrm{s}$, (c) $\omega=77 \mathrm{rad} / \mathrm{s} . R a=0 \mathrm{~m}, \mu=0.0067 \mathrm{~kg} /(\mathrm{m} \cdot \mathrm{s})$.

Finally, Figure 7 depicts the volume fraction of the molten metal along an imaginary vertical line that runs through the center of the mold for the considered values of the angular velocity. For $\omega=50 \mathrm{rad} / \mathrm{s}$ and $\omega=60 \mathrm{rad} / \mathrm{s}$, a significant mass of molten metal rests at the lower quarter of the mold. A uniform layer of molten metal is obtained for $\omega=77 \mathrm{rad} / \mathrm{s}$, as it is seen in Figure 7(c). Considering the approximate nature of the computer simulations, the thickness of the molten metal layer $(\delta)$ observed in Figure $7(\mathrm{c})$ is of the same order of magnitude to that obtained through Equations (3-6) using $R=0.1 \mathrm{~m}$ and $h=$ $0.05 \mathrm{~m}$, which gives $\delta=2.927 \times 10^{-3} \mathrm{~m}$.

\section{Conclusions}

Through the CFD technique, the distribution of molten metal and air phases in a 
horizontal centrifugal casting process was studied. Based on the results of computer simulations, the following conclusions can be drawn:

1) For the system considered, angular velocities less than $77 \mathrm{rad} / \mathrm{s}$, or $G$-factor less than 60, cause the emergence of the raining phenomenon and accumulation of the molten metal in the lower part of the mold.

2) On the contrary, angular velocities greater than $77 \mathrm{rad} / \mathrm{s}$ produces a constant value of the molten metal layer around the mold wall and prevent the emergence of the raining phenomenon.

3) During the initial stage of the process the molten metal viscosity contributes to homogenize the distribution of the molten metal in the centrifugal casting mold.

4) The roughness of the mold wall enhances the uniformity of the molten layer thickness just during the initial stage of the process.

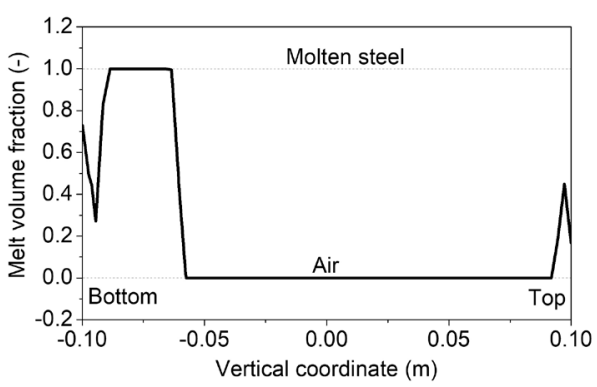

(a)

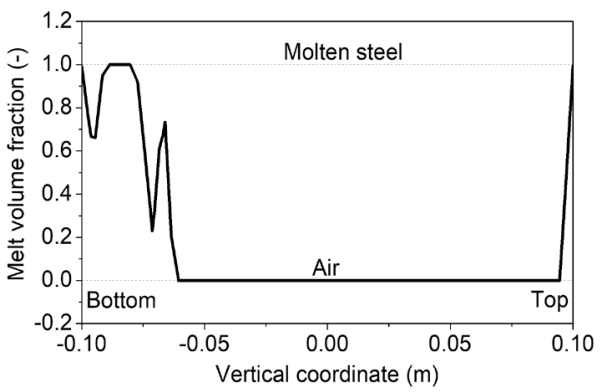

(b)

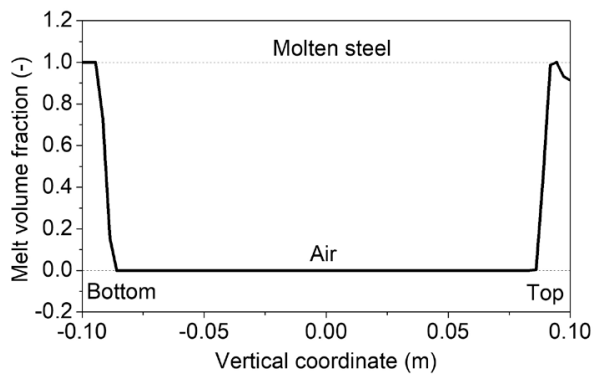

(c)

Figure 7. Volume fraction of the molten metal for $t=10 \mathrm{~s}$ along an imaginary vertical line that runs through the center of the mold for several values of the angular velocity. (a) $\omega=50 \mathrm{rad} / \mathrm{s}$, (b) $\omega=60 \mathrm{rad} / \mathrm{s}$, (c) $\omega=77 \mathrm{rad} / \mathrm{s} . R a=0 \mathrm{~m}, \mu=0.0067 \mathrm{~kg} /(\mathrm{m} \cdot \mathrm{s})$. 
Future work must be done given that heat transfer and solidification were not considered here.

\section{Conflicts of Interest}

The authors declare no conflicts of interest regarding the publication of this paper.

\section{References}

[1] Wei, S. and Lampman, S. (2008) Centrifugal Casting. ASM Handbook, 15, 667-673. https://doi.org/10.31399/asm.hb.v15.a0005257

[2] https://www.scribd.com/document/413060780/Metal-Castings

[3] Beeley, P. (2001) Foundry Technology. 2nd Edition, Butterworth, Woburn, MA.

[4] Hashmi, M.S.J. (2014) Comprehensive Materials Processing. Elsevier, Amsterdam.

[5] Chirita, G., Stefanescu, I., Soares, D. and Silva, F.S. (2006) Centrifugal versus Gravity Casting Techniques over Mechanical Properties. Anales de Mecanica de la Fractura, 1, 317-322.

[6] Esaka, H., Kaneko, H., Watanabe, D. and Shinozuka, K. (2013) Model Experiment for Horizontal Centrifugal Casting Process. Proceedings of the 8 th Pacific Rim International Congress on Advanced Materials and Processing TMS, 4-9 August 2013, Waikoloa, Hawaii, 2549-2556. https://doi.org/10.1007/978-3-319-48764-9_316

[7] Bohacek, J. Kharicha, A., Ludwig, A., Wu, M., Para, A., Brandner, M., Elizondo, L. and Trickl, T. (2016) Free-Surface Flow in Horizontally Rotating Cylinder: Experiment and Simulation. IOP Conference Series. Materials Science and Engineering, 143, 1-7. https://doi.org/10.1088/1757-899X/143/1/012036

[8] Keerthiprasad, K.S., Murali, M.S., Mukunda, P.G. and Majumdar, S. (2011) Numerical Simulation and Cold Modeling Experiments on Centrifugal Casting. Metallurgical and Materials Transactions B, 42, 144-155. https://doi.org/10.1007/s11663-010-9402-4

[9] Keerthiprasad, K.S., Murali, M.S. and Mukunda, P.G. (2010) Analysis of Fluid Flow in Centrifugal Casting. Frontiers in Materials Science China, 4, 103-110. https://doi.org/10.1007/s11706-010-0005-4

[10] Yuan, M.H., Cao, L.L., Xu, Y.Z. and Song, X.D. (2014) Numerical Simulation on Effects of Electromagnetic Force on the Centrifugal Casting Process of High Speed Steel Roll. Modeling and Numerical Simulation of Material Science, 4, 20-24. https://doi.org/10.4236/mnsms.2014.41004

[11] Kharicha, A., Bohacek, J., Ludwig, A. and Wu, M. (2015) Modified Shallow Water Equations with Application for Horizontal Centrifugal Casting of Rolls. Journal of Fluids Engineering, 137, Article ID: 11105. https://doi.org/10.1115/1.4030760

[12] Kaschnitz, E. (2012) Numerical Simulation of Centrifugal Casting of Pipes. IOP Conference Series: Materials Science and Engineering, 33, 1-6. https://doi.org/10.1088/1757-899X/33/1/012031

[13] Jimenez, J. (2004) Turbulent Flows over Roughwalls. Annual Review of Fluid Mechanics, 36, 173-196.

[14] Taylor, J.B., Carrano, A.L. and Kandlikar, S.G. (2006) Characterization of the Effect of Surface Roughness and Texture on Fluid Flow-Past, Present, and Future. International Journal of Thermal Sciences, 45, 962-968. https://doi.org/10.1016/j.ijthermalsci.2006.01.004 
[15] http://ccmcotulsa.com/visible-defects-raining/

[16] Ferziger, J.H. and Peric, M. (1999) Computational Methods for Fluid Dynamics. Springer, Berlin.

[17] Bird, R.B., Stewart, W.E. and Lightfoot, E.N. (2002) Transport Phenomena. Wiley, New York, N.Y.

[18] Hirt, C.W. and Nichols, B.D. (1981) Volume of Fluid (VOF) Method for the Dynamics of Free Boundaries. Journal of Computational Physics, 39, 201-225. https://doi.org/10.1016/0021-9991(81)90145-5

[19] Launder, B.E. and Spalding, D.B. (1972) Mathematical Models of Turbulence. Academic Press, London, UK.

[20] Groover, M.P. (2012) Fundamentals of Modern Manufacturing. Wiley, Hoboken, NJ.

[21] Poirier, D.R. and Geiger, G.H. (2016) Transport Phenomena in Materials Processing. Springer, Cham, Switzerland. https://doi.org/10.1007/978-3-319-48090-9 